\title{
A Study on the Effectiveness of College Students' Volunteer Service - Taking the Communist Youth League Care for the Children of Migrant Workers' Volunteer Service Action Colorful Cabin as a Case*
}

\author{
Guoling Pan \\ Baicheng Normal University \\ Baicheng, China 137000
}

\begin{abstract}
In order to understand the status quo of volunteer service and explore the basic rules of volunteer service development, based on the evaluation of the development level of volunteer service, the paper analyzes the main influencing factors of college students' volunteer service, and focuses on how to promote the standardization of volunteer service activities and further build volunteer service management and operation system with Chinese characteristics to solve the problems in the process of college students' volunteer service in China.
\end{abstract}

Keywords-effectiveness; college students' volunteer service; the children of migrant workers

\section{INTRODUCTION}

Along with the historical process of socialism with Chinese characteristics, China's volunteer service industry has developed rapidly, and voluntary service organizations have emerged. Volunteer service is a supplement to the state function. Once the volunteer service activity has evolved into a formal service that goes through the field and shouts slogans, it will inevitably result in waste of resources, affecting the image of the party and the government, and failing to achieve the solution of the dedication of the main body of the activity and the solution of the service object. The solution to the effectiveness of volunteer service is the fundamental issue that determines whether college volunteer service activities can continue.

With regard to the research on college students' volunteer service, the future development trend should be based on the standardization of the construction of college students' volunteer service system, and the important content of the construction of volunteer service system standardization is the effectiveness of college students' volunteer service. Through the research on the effectiveness of college students' volunteer service, we will promote the standardization of the volunteer service system, and then achieve the volunteer service to effectively solve the problems existing in the real society and supplement the state

*[Fund Project] This article is the phased achievement of "Thirteenth Five-Year" Social Science Research Project of Jilin Provincial Department of Education function.

Along with that volunteer service is vigorously carried out, the problems in China's volunteer service are constantly emerging. The more prominent problem is that the effectiveness of college students' volunteer service is not strong. At present, college volunteer service lacks reflection, investigation, research and feedback, and the effect of volunteer service does not reach the expected goal.

For example, the "Communist Youth League Care for Migrant Workers' Volunteer Service Action Colorful Cabin" in the hospital, through the specific and microscopic anatomy of the colorful cabins of our hospital, it has a resonating enlightenment for similar institutions and to improve the volunteer service for college students. Effectiveness provides theoretical reference and experience. To understand the status quo of volunteer service and assess the development level of volunteer service, then through analyzing the main influencing factors of college students' volunteer service and exploring the basic laws of volunteer service development, the paper solves the problems in the process of college students' volunteer service and promotes the standardization of volunteer service activities, and at last build Chinese unique volunteer service management operation system.

\section{OVERVIEW OF THE VOLUNTEER SERVICE OF COLORFUL CABIN}

What is the "Communist Youth League Care for Migrant Workers' Children Volunteer Service Action Colorful Cabin"? Why do you want to carry out it? What are the contents of it?

The "Colorful Cabin" is an important part of the Communist Youth League's volunteer service for the children of migrant workers (referred to as "the Communist Youth League Caring Action"). It is to strengthen the social mobilization and attract the participation of all parties. It is an important part of the joint efforts to promote the volunteer service of the children of migrant workers. The Central Committee of the Communist Youth League and the Chinese Youth Volunteers Association organized a special promotion 
conference for volunteers for children of migrant workers. Dozens of enterprises actively fulfilled their social responsibilities and participated in various ways including volunteers, donor funds and project cooperation. The construction and operation funds of the cabins are mainly financed by the society. The companies of supporting fund can participate in the work of the lodge through the form of naming, arranging the employees of the companies to carry out volunteer service. The cabin is equipped with computers, TVs, books and various cultural and sports items for the children. The children of migrant workers can make video calls with parents working outside the home, do homework under the guidance of young volunteers, learn to play the keyboard, and chat with the psychological counseling volunteers, talk and play games. It is a position for young volunteers to provide regular volunteer services for children of migrant workers. It is a place for children to study and participate in activities after school. It is also a standardized carrier for party and government support and integration of social resources.

\section{CURrent Status of Volunteer SERVICE ACTIVITIES IN THE COLORFUL CABIN}

The college's colorful cabin has lasted for 5 years since its establishment. Up to now, the "Colorful Cabin" volunteer service has helped 28 children of migrant workers. It has carried out various brand activities for more than 70 times, coordinated 18 departments, participated in more than 480 service volunteers, donated more than 10,000 Yuan, 6,500 books and 54 sets of learning supplies. Just in March this year, the first class of students has graduated, and we have already welcomed the second batch of students.

In the past five years, we have collected, organized and archived information on the entire process of "Colorful Cabin" volunteer service, including the formulation of the previous activity plan, the content and the effect of the event. And a card for each member of the colorful cabin has been set up, and archived all the information of the event.

Looking at the colorful cabin volunteer service activities, the lack of maximization of work effectiveness is the biggest problem facing the current colorful cabin volunteer service activities.

\section{THE SPECIFIC PERFORMANCE OF EFFECTIVENESS FOR THE VOLUNTARY SERVICE}

The specific performance of the Communist Youth League's care for the children's colorful cabin volunteer service is not strong:

\section{A. Volunteer Service Parties Do not Recognize the Voluntary Service}

Since the volunteer service is for the children of rural migrant workers at school, most of the time for the activities is for the students during their school days. The development of the volunteer service of the colorful cabins takes up the self-study time of the students. And for the long-term continuous volunteer service, the students' school does not cooperate. The two parties often communicate and mediate on this, so the specific implementation of the colorful cabin has been greatly affected.

\section{B. Lack of Volunteer Service Social Security System}

The lack of university volunteer service security system is a common problem faced by all volunteer service projects in colleges and universities in China. It is mainly manifested in the explicit provisions and financial support of national and local laws and regulations. As a result, voluntary services in universities in China are self-financing and selfresponsible. At present, volunteering services have not yet become widely recognized as a social consensus, and the sources of volunteer service groups are relatively single. The shortage of funds is a major issue affecting the sustainability of volunteer services. Many voluntary service organizations lack stable and reliable sources of funding, and there is no guarantee for the development of volunteer service activities.

\section{Lack of Long-term Volunteer Service Mechanisms}

The effect of volunteer service requires a long-term process, and one or several volunteer services, such as water, lack of systematic planning and lack of long-term mechanism. Volunteer service did not form a unified and standardized incentive mechanism, project mechanism; file management system, etc., resulting in insufficient management of the volunteer service team and insufficient cohesiveness, which hindered the development of volunteer service to a certain extent.

\section{Lack of Professional Training for Volunteers}

Due to the uneven quality of volunteers, most people are engaged in "popular" volunteer service that is simple and lacks certain professional and technical content. The service effect is not satisfactory. Volunteer service involves many areas with strong professionalism, and requires volunteers to have basic skills such as communication and organization. However, the training of volunteer organizations has not been standardized, which is not conducive to the sustainable development of volunteer service activities. Therefore, schools must establish specialized training institutions, stipulate special training time, and designate special personnel to conduct training for those who participate in the training. Colleges and universities should speed up the construction of volunteer electronic files, register the electronic files in the network management system with volunteers to participate in the service and link them with the quality of the services. By establishing a voluntary information base and storing volunteer materials in a comprehensive, systematic and scientific way, the volunteer team is more stable, work continuity is enhanced, and service quality is further improved. The improvement of the longterm mechanism of volunteer service is large and complex system engineering. It still needs the strong support of the state, all walks of life and students. By establishing a longterm mechanism of volunteer service, we can create a good volunteer service environment and become a volunteer service business. Further development creates favorable conditions. 


\section{THE COUNTERMEASURES FOR SOLVING THE} EFFECTIVENESS OF VOLUNTEER SERVICE

Establishing a standardized work system for volunteer service is the key to improving the effectiveness of college students' volunteer service. The following strategies are proposed for the above problems:

First, the docking school should try to choose primary schools and junior high schools in rural areas. Because students need services, so volunteer service is valuable and can be recognized by them. However, due to the long distance, it may increase the difficulty of volunteering.

Second, optimize the volunteer service security system. We will formulate relevant laws and regulations and increase financial support from the government. Only when the basic rights and interests of volunteers are guaranteed can volunteers better provide efficient and professional services to the society.

Third, establish a long-term voluntary service mechanism. Under the leadership of the cadres of the regiments, the league organizations at all levels grasp the innovation mechanism of the pulse of the times, constantly improve the process and norms of volunteer service work, establish and improve the guarantee mechanism of volunteer service, and at the same time require constant voluntary service to achieve the effect of volunteer service to serve the public. It is necessary to establish a long-term working mechanism led by the Youth League Committee and coordinated coordination between relevant functional departments and secondary departments to ensure that the volunteer service of college students is implemented. It is necessary to improve the long-term operation mechanism of college students' volunteer service activities, and strengthen the construction of student volunteer service organizations such as the College Student Volunteer Service Alliance, the Volunteer Service Teams of all departments, and the student charity community.

Forth, standardize volunteer service organizations. The measures are: set up the leading group of university students' volunteer service, and coordinate the volunteer service of the whole school as a whole, standardize the volunteer registration system, collect information about the registration and participation of service volunteers, and ensure the recruitment of volunteers; According to the special skills and hobbies of volunteers and the needs of service posts, divide the volunteers into scientific groups, define tasks and fulfill responsibilities.

Fifth, enrich the content of volunteer service activities. The purpose of carrying out youth volunteer service is to deliver positive social energy through volunteer service activities. For example, organizing community volunteer services, focusing on the elderly, disabled, children of migrant workers and left-behind students (children) in the community, generally carrying out community volunteer service activities such as helping the elderly, helping the disabled, helping the needy, seeking emergency help, benefiting the people and promoting safety knowledge such as self-protection and relief, disaster prevention and reduction education.
Sixth, improve the rules and regulations for volunteer service. The measures are: improve the construction of volunteer service organizations, standardize volunteer activities, enhance the discipline of volunteer service teams, improve the quality and efficiency of work in various departments, so that there are rules to follow, and the work of the volunteer service team can be smoothly carried out. .

Seventh, create the relationship between volunteer and service objects. The classification of service relationship between volunteers and service objects is of great significance for future activities of volunteers. The first is the active-passive voluntary service relationship. Volunteer is completely active, the service object is completely passive, its characteristics and key points are: what to do for the service object. Most of the volunteer services under this kind of relationship are one-way. The technical content of the volunteer services may be low, and the volunteers are easy to get bored. Therefore, more attention should be paid to them. The second is the guiding - cooperative voluntary service relationship. Volunteers are active, the service objects have certain initiative, the opinions provided by volunteers have certain authority and are respected by the service objects.

Voluntary service under this kind of relationship is semitwo-way. In the process of service, more attention should be paid to the requirements of service objects to make the service better. The third is the mutual participation voluntary service relations. Volunteers and service objects have the same degree of initiative to participate in the decision and implementation of volunteer service. Their characteristic and main points are: help service object self-cure. Under this kind of relationship, the requirements of volunteer service for volunteers are higher than those of the first two kinds. Therefore, when carrying out the service, attention should be paid to the ability and level of volunteers to ensure the smooth development of the service.

The above three kinds of service relationships are centered on the role of the service object. Volunteers adopt appropriate interpersonal relationships of voluntary service, and perform corresponding voluntary services in terms of what to do for the service object, telling the service object what to do, and helping the service object deal with problems.

Eighth, carry out volunteer service training. The measures are: to guide the content of volunteer service, record the content and quality of the service and make suggestions to improve the sense of volunteer service responsibility.

By improving the effectiveness of volunteer service work, we should give full play to the main role of college students in volunteer service activities and cultivate dedication and service awareness. We improve the coordination, cooperation, and management and organization ability of college students by improving the effectiveness of volunteer service. Through improving the effectiveness of volunteer service and combining with their own professional advantages to better carry out relevant volunteer service activities, and professional skills is enhanced. Through improving the effectiveness of volunteer service work, the level of college students' volunteer service work is optimized, 
and the sense of ownership and social responsibility are enhanced, and the growth of college students are promoted into talents. By improving the effectiveness of volunteer service work and improving the scientific research level of the instructor studio, theoretical support is provided for the volunteer service work of the youth league committee. We should promote the extensive development of volunteer services and promote the building of spiritual civilization by improving the effectiveness of volunteer services. We should promote innovation in social governance and maintain social harmony and stability by improving the effectiveness of voluntary services. Regional economic development is promoted by improving the effectiveness of voluntary services.

"Dedication, friendship, mutual assistance and progress" is the volunteer spirit advocated by volunteer service. This spirit not only inherits the traditional virtues of helping the Chinese people to help others, helping the poor and poverty alleviation, but also reflects the basic requirements for building a harmonious socialist society. The profound cultural heritage of the Chinese nation has distinct characteristics of the times. Vigorously promoting and practicing the spirit of volunteerism and developing volunteer services will surely be promising.

Volunteers' service activities are a worldwide charity event and have been widely recognized and highly supported by society. As the main force of Chinese youth volunteer service, college students' volunteer service is facing the problems of unsatisfactory organizational management and insufficient effectiveness, which seriously restricts the healthy and effective development of volunteer service activities. In view of the current situation of college students' volunteer service, the author proposes to optimize the volunteer service guarantee system and standardize the volunteer service organization. Through establishing a longterm volunteer service mechanism and the effectiveness of college students' volunteer service will be continuously improved. It is believed that through continuous efforts, the volunteer culture of college students will be continuously carried forward.

\section{CONCLUSION}

In conclusion, volunteer service should be able to further develop the function of ideological and political education through the government and efficient and reasonable cooperation. To use this carrier, we must improve the emphasis on college students' volunteer service activities and guide students to actively participate in volunteer service activities with reflecting the effectiveness of volunteering activities.

\section{REFERENCES}

[1] Yang Nan, Chen Jieming, Wang Kexin, Ma Wensai. Research on the Status Quo of College Students' Volunteer Service and Countermeasures[J].Talent, 2017,6. (in Chinese)

[2] Wang Fangying, Chen Xiaohong. Analysis of the current situation of college volunteer service operation management [J]. China Social News. 2018, 5. (in Chinese)
[3] Zhong Rong. The Enlightenment of Volunteer Service Operation Mechanism in Developed Countries on the Construction of Longterm Mechanism of Volunteer Service in Colleges and Universities [J]. China Market, 2018, 3. (in Chinese)

[4] Colorful Holidays Happy Childhood - Youth Volunteers Care for Left-behind Children's "Colorful Holidays" Volunteer Service Project [J]. Chinese Communist Youth League. 2018, 9. (in Chinese)

[5] Sui Hong. Caring for the volunteer service of migrant children's children - let the children feel the great love of society [J]. Xiaokang, 2015, 2. (in Chinese)

[6] "Let's approach the colorful cabins and experience the colorful classrooms" - micro-activities blew the children's assembly number of the migrant workers [J]. Golden Age, 2012, 11. (in Chinese)

[7] Dai Xiufeng. Cultivation and Base Construction of Volunteer Service Brands in Colleges and Universities [J]. Journal of Beihua University of Aeronautics and Astronautics, 2018, 2. (in Chinese)

[8] Chen Yanqi. Problems and Countermeasures of College Young Volunteers Participating in Social Governance [J]. Management Observation, 2018, 2. (in Chinese)

[9] Sun Wei. Research on Long-term Mechanism of Volunteer Service Activities in Colleges and Universities [J]. Journal of Heihe University, 2018, 9. (in Chinese)

[10] Xie Chenzhi. Research on the Innovation of College Students' Volunteer Service Model from the Perspective of Practical Education[J]. Times Education, 2018, 2. (in Chinese) 